\title{
Mexico, diabesity, tacos and mariachi
}

\section{Mini review}

In Mexico has declared diabetes a public health emergency, across the OECD, over 93 million adults - or $7 \%$ of all adults - were diabetics in 2015. ${ }^{1}$ The International Diabetes Federation estimates that a further 33 million adults have undiagnosed diabetes in OECD countries. Diabetes prevalence is highest in Mexico, where more than $15 \%$ of adults have diabetes. Diabetes prevalence is also high in Turkey, the United States and Chile, where $10 \%$ or more of adults were diabetics. In contrast, less than $5 \%$ of adults suffered from diabetes in Estonia, Ireland, luxembourg, Sweden and the United Kingdom. ${ }^{2}$

Rising rates of obesity combined with a genetic predisposition for Type 2 diabetes has caused a slow steady rise in the condition in Mexico over the last 40 years. For many people with diabetes in Mexico, managing the condition is a constant and significant challenge. The obesity problem is in part a side effect of Mexico's economic progress. As wages have risen, the average daily intake of calories has soared. For a example, A person who has to work 8 or 10 hours has to eat what's at hand, what's available, tacos, tamales, quesadillas, fat sandwiches called tortas, the roast pork taquitos and simmering beef barbacoa is a difficult to follow a diabetic diet. ${ }^{3}$

In 2012 Mexico was the world's top per capita consumer of soda in the world guzzling 176 liters per person per year, according to the Mexican government. That's nearly 500 cans of soda for every man, woman and child. Soda is practically the national drink, a lifestyle in Mexico. Diabetes costs the Mexican health care system billions of dollars each year, to get excellent control of diabetes costs a lot of money as renting an apartment or a house for a Mexican family. ${ }^{4}$ The disease can lead to serious eye problems including blindness, nerve damage that requires amputations and kidney failure, among other issues, Patients don't want to accept that they have a disease for which there is no cure. The federal government has implemented several strategies to reduce mortality caused by chronic noncommunicable diseases (CNTD). One example is the development of medical units specialized in the care of CNTD (i.e. overweight, obesity, cardiovascular risk and diabetes), named UNEMES (from its Spanish initials). These units -consisting of an ad-hoc, trained, multi-disciplinary team- will provide patient education, help in the resolution of obstacles limiting treatment adherence, and involve the family in patient care. ${ }^{5}$

The difficulties presented in the adhesion to the treatment, low perceived susceptibility and mean perceived severity when facing the complications of diabetes overweight, obesity, cardiovascular risk
Volume 2 Issue 2 - 2018

\author{
Eleazar González Arriaga \\ Integrated Care Private practice, Director UNEME San Luis \\ Potosi, Mexico
}

Correspondence: Eleazar González Arriaga, Integrated Care Private practice, Director UNEME San Luis Potosi, Mexico, Email epewrez@hotmail.com

Received: February 22, 2018 | Published: March 23, 2018

and diabetes is a hard challenge. Mexico has seen a rapid increase in obesity, with the number of people categorized as overweight and obese tripling over the last four decades. Type 2 diabetes is often considered a lifestyle disease because it's far more likely to develop in people who are overweight, therefore Diabesity , taco's and mariachi is dangerous combination.

\section{Acknowledgements}

None.

\section{Conflict of interest}

The author declares no conflict of interest.

\section{References}

1. https://www.idf.org/

2. Healt at a glance 2017 OECD Indicators. Israel: 2017.

3. Menke A, Sarah Casagrande, Linda Geiss, et al. Prevalence of and Trends in Diabetes Among Adults in the United States, 1988-2012. JAMA. 2015;314(10):1021-1029.

4. NCD Risk Factor Collaboration. Worldwide Trends in Diabetes Since 1980: A Pooled Analysis of 751 Population-based Studies with $4 \cdot 4$ Million Participants. The Lancet. 2016;387(10027):1513-1530.

5. Córdova-Villalobos JA, Barriguete-Meléndez JA, Lara-Esqueda A, et al. Chronic non-communicable diseases in Mexico: epidemiologic synopsis and integral prevention. Salud pública Méx. 2008;50(5):419-427. 